\title{
DYNAMIC PROBLEM OF FORMATION OF SECURITIES PORTFOLIO UNDER UNCERTAINTY CONDITIONS
}

\author{
Lev Raskin ${ }^{1}$ \\ Oksana Sira ${ }^{1}$ \\ topology@ukr.net \\ Tetiana Katkova \\ Department of Cyber security \\ University of Customs and Finance \\ 2/4 V. Vernadsky str., Dnipro, Ukraine, 49000 \\ 777-kit@ukr.net \\ ${ }^{1}$ Department of Distributed information systems and cloud technologies \\ National Technical University "Kharkiv Polytechnic Institute" \\ 2 Kyrpychova str., Kharkiv, Ukraine, 61002
}

\begin{abstract}
The analysis of known methods for solving the problem of forming a portfolio of securities in the face of uncertainty is carried out. Traditionally, the problem is solved under the assumption that for each type of asset, the values of the main statistical characteristics of the random value of their profitability (mathematical expectation and variance) are known. At the same time, the variance of portfolio returns, which is minimized, is used as a criterion for portfolio optimization. Two alternative approaches to solving the formulated problem are proposed. The first of them provides a decision on the criterion of the probability that the random total portfolio return will not be lower than the given. It is assumed that the random return for each type of asset is distributed normally and the statistical characteristics of the respective densities are known. The original problem is reduced to the problem of maximizing the quadratic fractional criterion in the presence of linear constraints. To solve this non-standard optimization problem, a special iterative algorithm is proposed that implements the procedure for sequential improvement of the plan. The method converges and the computational procedure for obtaining a solution can be stopped by any of the standard criteria. The second approach considers the possibility of solving the problem under the assumption that the distribution densities of random asset returns are not known, however, based on the results of preliminary statistical processing of the initial data, estimates of the values of the main numerical characteristics for each of the assets are obtained. To solve the problem, a new mathematical apparatus is used - continuous linear programming, which is a generalization of ordinary linear programming to the case when the task variables are continuous. This method, in the considered problem, is based on solving an auxiliary problem: finding the worst-case distribution density of a random total portfolio return at which this total return does not reach an acceptable threshold with maximum probability. Now the main minimax problem is being solved: the formation of the best portfolio in the worst conditions. The resulting computational scheme leads to the problem of quadratic mathematical programming in the presence of linear constraints. Next, a method is proposed for solving the problem of forming a portfolio of securities, taking into account the real dynamics of the value of assets. The problem that arises in this case is formulated and solved in terms of the general theory of control, using the Riccati equation.

Keywords: formation of a portfolio of securities, worst-case density distribution of portfolio returns, fractional non-linear optimization problem, Riccati control.
\end{abstract}

DOI: $10.21303 / 2461-4262.2019 .00985$

\section{Introduction}

The task of forming a portfolio of securities belongs to the widely represented class of tasks of rational distribution of resources [1-4]. The mathematical formulation of the problems of this class leads to a standard scheme: to find a set of variables defining the desired distribution of resources, delivering an extreme value, as a rule, to a nonlinear criterion and satisfying linear constraints. Problems of this type are solved by well-known mathematical programming methods [4-6]. An essential feature of resource allocation problems in the modern formulation is to take into account the uncertainty of the source data. Traditional approaches to the formulation and solution of such problems use a probabilistic interpretation of the uncertainty of the param- 
eters of the problem, which leads to stochastic programming models [7-11]. The principal drawback of these models is the lack of accuracy in the conditions of a small sample of initial data, when there is no possibility of an adequate description of the distribution densities of random parameters of the problem. In this case, it is natural to use methods that implement the minimax approach taking into account the "worst" distribution densities of random parameters [12, 13]. This approach provides an overly cautious, guaranteed solution, which is not always acceptable. An alternative approach can be based on the description of the uncertain parameters of the problem in terms of the theory of fuzzy sets [14-18].

The mathematical model of the problem of forming a portfolio of securities in a probability-theoretical formulation has the following form [19].

Let there be an asset market and

$R_{j}$ - random efficiency of the $\mathrm{j}$-th type of assets (random profit from the sale of a portfolio entirely consisting of assets of the $j$-th type), $j=(1,2, \ldots, n)$;

$x_{j}$ - the share of the $\mathrm{j}$-th type of assets in the portfolio;

$m_{j}=E\left[R_{j}\right]-$ average value of the random investment efficiency in the $\mathrm{j}$-th form of assets, $E[\bullet]-$ symbol of the operator of calculating the mathematical expectation, $M=\left(m_{1}, m_{2}, \ldots, m_{n}\right)$.

Then

$$
R=\sum_{i=1}^{n} R_{j} x_{j}
$$

is a random portfolio performance, and

$$
m=\sum_{j=1}^{n} E\left[R_{j}\right] x_{j}=\sum_{j=1}^{n} m_{j} x_{j}=M X
$$

is its average efficiency (or average profit) corresponding to the plan $X=\left(x_{1}, x_{2}, \ldots, x_{n}\right)^{\mathrm{T}}$.

The variance of portfolio performance (risk) is calculated as follows:

$$
D(x)=M\left[(m-R)^{2}\right]=M\left[\left(\sum_{j=1}^{n} m_{j} x_{j}-\sum_{j=1}^{n} R_{j} x_{j}\right)^{2}\right]=M\left[\left(\sum_{j=1}^{n}\left(m_{j}-R_{j}\right) x_{j}\right)^{2}\right]=\sum_{i=1}^{n} \sum_{j=1}^{n} v_{i j} x_{i} x_{j}=X^{T} V X
$$

where

$$
v_{i j}=M\left[\left(m_{i}-R_{i}\right)\left(m_{j}-R_{j}\right)\right], \quad V=\left(v_{i j}\right) .
$$

Moreover, if random efficiency values for assets of different types are not correlated, then $v_{i j}=D_{j}, \quad j=1,2, \ldots, n$.

Now the portfolio optimization task is formulated as follows: to find a set $X=\left(x_{1}, x_{2}, \ldots, x_{n}\right)$, minimizing the variance of the risk of investing funds (1) and providing a given level $m_{\text {giv }}$ of average profit.

The mathematical model of the problem has the form: find a non-negative vector $X$ that minimizes (1) and satisfies the constraints

$$
\begin{gathered}
\sum_{j=1}^{n} m_{j} x_{j}=M X=m_{g i v}, \\
\sum_{j=1}^{n} x_{j}=I X=1, \quad I=(1,1, \ldots, 1), \quad x_{j} \geq 0 .
\end{gathered}
$$

The resulting problem is a canonical quadratic programming problem. Its solution by the method of indefinite Lagrange multipliers leads to the following result 


$$
X^{*}=V^{-1} C^{T}\left(C V^{-1} C^{T}\right)^{-1} d, C=\left(\begin{array}{c}
I \\
M
\end{array}\right), d=\left(\begin{array}{c}
1 \\
\text { giv }
\end{array}\right) .
$$

Formula (4) defines the desired vector $X$, which determines the portfolio structure.

For many real optimization problems in which the numerical values of the criterion depend on random parameters, it is advisable to abandon optimization on average [19]. Moreover, in the task of forming a portfolio of securities, the corresponding mathematical model takes a different form. The statement of the problem: to find a distribution $\left\{x_{j}\right\}$, satisfying (2), (3) and maximizing the probability that the random total profit from portfolio implementation will exceed a certain threshold $-R_{0}$. If, by virtue of the central limit theorem of probability theory, assume that the total profit is a normally distributed random variable, then this probability will be described by the ratio:

$$
P\left(R \geq R_{0}\right)=\int_{R_{0}}^{\infty} \frac{1}{\sqrt{2 \pi} \sigma_{\Sigma}} \exp \left\{-\frac{\left(R-\mu_{1}\right)^{2}}{2 \sigma_{\Sigma}^{2}}\right\} \mathrm{d} R, \quad \mu_{1}=\sum_{i=1}^{n} m_{j} x_{j}, \quad \sigma_{\Sigma}^{2}=\sum_{j=1}^{n} \sigma_{j}^{2} x_{j}^{2} .
$$

Now the task of forming the portfolio structure is as follows: find a vector $X$ that maximizes (5) and satisfies (2), (3).

It is clear that maximization (6) is equivalent to the maximization problem

$$
L(x)=\frac{\left(R_{0}-\mu_{1}\right)^{2}}{\sum_{\sigma_{j}^{2} x_{j}^{2}=1}^{n} \sigma_{j}^{2} x_{j}^{2}}=\frac{\left[R_{0} \sum_{j=1}^{n} x_{j}-\sum_{j=1}^{n} m_{j} x_{j}\right]^{2}}{\sum_{j=1}^{n} \sigma_{j}^{2} x_{j}^{2}}=\frac{\left(\sum_{j=1}^{n}\left(R_{0}-m_{j}\right) x_{j}\right)^{2}}{\sum_{j=1}^{n} \sigma_{j}^{2} x_{j}^{2}}=\frac{\left(\sum_{j=1}^{n} d_{j} x_{j}\right)^{2}}{\sum_{j=1}^{n} \sigma_{j}^{2} x_{j}^{2}} .
$$

The obtained problem of fractional-quadratic programming with linear constraints is solved using the sequential plan improvement procedure [4].

In problems with a small sample of initial data, the assumption of the normality of their distribution is overly binding. In this situation, [12-14] proposed a minimax technology for solving such problems under the assumption of the "worst" distribution density of its random parameters. In accordance with this technology, the solution of the problem is implemented in two stages. First, for the observed set $\left\{x_{j}\right\}$, satisfying (2), (3), the "worst" distribution density of a random value of the total profit with known mathematical expectation and variance is found. In this case, the probability of not reaching a given threshold $R_{0}$ should be maximum. Then, taking into account the "worst" density, the problem of calculating the distribution of assets that minimizes the probability of not exceeding $R_{0}$ is solved. When finding the "worst" distribution density, the mathematical expectation $\mu_{1}$ and variance $\mu_{2}$ of a random profit are assumed to be known.

The problem of finding the "worst" distribution density is formulated as follows [12]: find the function $x^{*}(t)$, maximizing the functional

$$
P(x(t))=\int_{0}^{R_{0}} x(t) \mathrm{d} t
$$

and satisfying restrictions

$$
\int_{0}^{\infty} x(t) \mathrm{d} t=1, \int_{0}^{\infty} t x(t) \mathrm{d} t=\mu_{1}, \int_{0}^{\infty} t^{2} x(t) \mathrm{d} t=\mu_{2}=\mu_{1}^{2}+\sigma^{2}
$$

The resulting problem is the canonical problem of continuous linear programming. As shown in [12], the "worst" density $x^{*}(t)$ must be sought in the form of a weighted linear combination of delta functions, that is

$$
x^{*}(t)=\sum_{j=1}^{n} x_{j} \delta\left(t-t_{j}\right) .
$$


In this case, the problem reduces to determining unknown values maximizing $\left(x_{j}, t_{j}\right)$, $j=1,2, \ldots, n$, (7) and satisfying constraints (8), (9). The solution of the problem, as shown in [12], leads to the desired function

$$
x^{*}(t)=\frac{\mu_{2}-\mu_{1}^{2}}{\mu_{2}-2 \mu_{1} T_{0}+T_{0}^{2}} \delta\left(t-T_{0}\right)+\frac{\mu_{1}^{2}-2 \mu_{1} T_{0}+T_{0}^{2}}{\mu_{2}-2 \mu_{1} T_{0}+T_{0}^{2}} \delta\left(t-\frac{\mu_{2}-\mu_{1} T_{0}}{\mu_{1}-T_{0}}\right) .
$$

Moreover, the maximum probability of a random variable falling into the interval $\left[0, R_{0}\right]$ is equal to

$$
P\left(x^{*}(t)\right)=\frac{1}{1+\frac{\left(\sum_{j=1}^{n} x_{j} m_{j}-R_{0}\right)^{2}}{\sum_{j=1}^{n} \sigma_{j}^{2} x_{j}^{2}}}
$$

The resulting ratio determines the objective function of the portfolio $\left\{x_{j}\right\}$ formation task for the "worst" random profit distribution density. Thus, the problem is reduced to finding a distribution that minimizes (11) and satisfies portfolio constraints.

A brief analysis of the known approaches to solving the problem of forming a portfolio of securities allows us to draw the following conclusions. The way to solve this problem and the methodology that implements it are determined by the nature of the uncertainty about the real value of the assets, as well as the level of confidence in the adequacy of its accepted analytical descriptions. Traditional approaches to solving the problem of forming a portfolio of securities use the technology of statistical analysis and rely on probability-theoretical tools. However, in conditions of high variability of the market situation, the analysis of the existing uncertainty is forced to be limited to small samples of the initial data, which leads to unsatisfactory accuracy in calculating the statistical characteristics of the model. This circumstance makes it promising to solve the problem of taking into account the emerging real uncertainty using the least demanding mathematical tools to describe this model - the theory of fuzzy sets [14-20]. The corresponding approach was implemented in [19]. Moreover, the original problem is reduced to optimizing the quadratic-fractional functional on the set of solutions of a system of linear algebraic equations.

A common drawback of traditional methods for solving the problem of forming a portfolio of securities is the use of an unrealistic assumption about the static nature of the problem. The rejection of this hypothesis leads to the formulation of the original problem in terms of the general theory of control.

\section{The dynamic task of forming a portfolio of securities}

The investment portfolio control problem is a special case of the general problem of control theory, which is formulated as follows $[21,22]$. Let's introduce the phase space of states of the control object by the coordinate system $X^{T}=\left(x_{1}, x_{2}, \ldots x_{n}\right)$, which values in the portfolio formation task determine its structure by type of stock. The model of motion of an object in this phase space is traditionally defined by a vector-matrix system of differential equations

$$
\dot{X}(t)=A X(t)+B U(t)+W(t)
$$

where $X(t)$ - the state vector of the system at time $\mathrm{t}, \operatorname{dim} X(t)=n \times 1$, which determines the distribution of the number of shares by type; $U(t)$ - control vector at time $t, \operatorname{dim} U(t)=n \times 1$, which defines the distribution of investments for the acquisition of shares by type; $W(t)$ - noise vector that turns off errors in estimating the value of stocks, $\operatorname{dim} W(t)=n \times 1 ; A-$ a numerical matrix, $\operatorname{dim} A=n \times n ; B-$ a numerical matrix. 
Regarding noise, let's assume that

$$
E\{W(t)\}=0, \quad E\left\{W(t) \times W^{T}(t)\right\}=K(t)
$$

The control problem is to find a control that minimizes the integral quadratic functional

$$
J(u)=\frac{1}{2} \int_{o}^{T_{0}}\left(\tilde{X}^{T}(t) Q \tilde{X}(t)+U^{T}(t) R U(t)\right) \mathrm{d} t
$$

on the set of solutions of the system of differential equations (1).

Here

$$
\tilde{X}(t)=X(t)-X^{0}(t)
$$

where $X^{0}(t)$ - the reference trajectory of the vector $X(t)$, dynamics approximating the set of samples of the components of the optimal vectors $X(t)$ at the moments $T_{1}, T_{2}, \ldots, T_{k}$;

$$
Q=\left(\begin{array}{llll}
q_{1} & & & 0 \\
& q_{2} & & \\
& & \ddots & \\
0 & & & q_{n}
\end{array}\right)
$$

is weight matrix reflecting the a priori view of the investor regarding the market value of assets;

$$
R=\left(\begin{array}{llll}
r_{1} & & & 0 \\
& r_{2} & & \\
& & \ddots & \\
0 & & & r_{n}
\end{array}\right)
$$

is control cost matrix.

The dynamic problem consists in finding the control $U(t)$, of minimizing functional (14) on the set of solutions of the system of differential equations (13).

The control of such a system, optimal on average, is determined by the relation [21]:

$$
U(t)=-C \tilde{X}(t)
$$

where

$$
C=R^{-1} B^{T} S
$$

$S-$ a solution to the Riccati equation

$$
\dot{S}=-S A-A^{T} S+S B R^{-1} B^{T} S-Q .
$$

As applied to the portfolio formation task, the matrices $A$ and $B$ are both diagonal and equal, i. e.

$$
A=B=\left(\begin{array}{llll}
a_{1} & & & 0 \\
& a_{2} & & \\
& & \ddots & \\
0 & & & a_{n}
\end{array}\right) .
$$


Elements of this matrix determine the levels of income from the sale of assets of the corresponding type.

Such a solution can be obtained if accept that all functional elements in the Riccati equation are constants. Moreover, as is known [21], there is a steady-state solution to this equation in which the elements of the matrix $S$ are also constants. Then

so

$$
-S A-A^{T} S+S B R^{-1} B^{T} S-Q=0,
$$

$$
\begin{aligned}
& -2\left(\begin{array}{cccc}
s_{1} a_{1} & & & 0 \\
& s_{2} a_{2} & & \\
& & \ddots & \\
0 & & & s_{n} a_{n}
\end{array}\right)+\left(\begin{array}{llll}
s_{1} & & & 0 \\
& s_{2} & & \\
& & \ddots & \\
0 & & & s_{n}
\end{array}\right)\left(\begin{array}{llll}
a_{1} & & & 0 \\
& a_{2} & & \\
& & \ddots & \\
0 & & & a_{n}
\end{array}\right) \times \\
& \times\left(\begin{array}{cccc}
r_{1} & & & 0 \\
& r_{2} & & \\
& & \ddots & \\
0 & & & r_{n}
\end{array}\right)^{-1}\left(\begin{array}{llll}
a_{1} & & & 0 \\
& a_{2} & & \\
& & \ddots & \\
0 & & & a_{n}
\end{array}\right)\left(\begin{array}{llll}
s_{1} & & & 0 \\
& s_{2} & & \\
& & \ddots & \\
0 & & & s_{n}
\end{array}\right)-
\end{aligned}
$$$$
-\left(\begin{array}{cccc}
q_{1} & & & 0 \\
& q_{2} & & \\
& & \ddots & \\
0 & & & q_{n}
\end{array}\right)=-2\left(\begin{array}{cccc}
s_{1} a_{1} & & & 0 \\
& s_{2} a_{2} & & \\
& & \ddots & \\
0 & & & s_{n} a_{n}
\end{array}\right)+\left(\begin{array}{llll}
s_{1} & & & 0 \\
& s_{2} & & \\
& & \ddots & \\
0 & & & s_{n}
\end{array}\right) \times
$$$$
\times\left(\begin{array}{cccc}
a_{1}^{2} / r_{1} & & & 0 \\
& a_{2}^{2} / r_{2} & & \\
& & \ddots & \\
& & & a_{n}^{2} / r_{n}
\end{array}\right)\left(\begin{array}{llll}
s_{1} & & & 0 \\
& s_{2} & & \\
& & \ddots & \\
0 & & & s_{n}
\end{array}\right)-\left(\begin{array}{llll}
q_{1} & & & 0 \\
& q_{2} & & \\
& & \ddots & \\
0 & & & q_{n}
\end{array}\right)=
$$

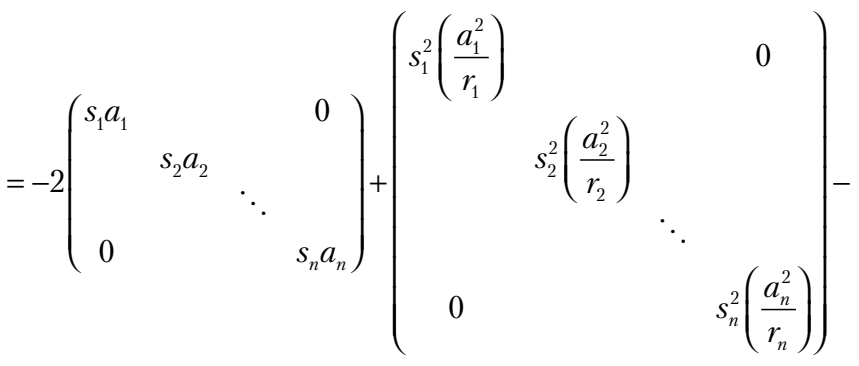

$$
\begin{aligned}
& -\left(\begin{array}{llll}
q_{1} & & & 0 \\
& q_{2} & & \\
& & \ddots & \\
0 & & & q_{n}
\end{array}\right)=0 .
\end{aligned}
$$

The structure of matrix equation (17) allows one to obtain its solution by solving $\mathrm{n}$ independent equations of the form

$$
\begin{gathered}
-2 s_{j} a_{j}+s_{j}^{2}\left(\frac{a_{j}^{2}}{r_{j}}\right)-q_{j}=0, \quad j=1,2, \ldots, n, \\
s_{j}^{2}-2 s_{j} \frac{r_{j}}{a_{j}}-\frac{q_{j} r_{j}}{a_{j}^{2}}=0,
\end{gathered}
$$

whence, choosing a positive root, let's obtain 


$$
s_{j}=\frac{r_{j}}{a_{j}}+\sqrt{\frac{r_{j}^{2}}{a_{j}^{2}}+\frac{q_{j} r_{j}}{a_{j}^{2}}}=\frac{r_{j}}{a_{j}}+\frac{r_{j}}{a_{j}} \sqrt{1+\frac{q_{j}}{r_{j}}}=\frac{r_{j}}{a_{j}}\left(1+\sqrt{1+\frac{q_{j}}{r_{j}}}\right) .
$$

Let's substitute (18) into (16). Wherein

$$
C=\left(\begin{array}{cccc}
\frac{1}{r_{1}} & & & 0 \\
& \frac{1}{r_{2}} & & \\
& & \ddots & \\
0 & & & \frac{1}{r_{n}}
\end{array}\right)\left(\begin{array}{llll}
a_{1} & & & 0 \\
& a_{2} & & \\
& & \ddots & \\
0 & & & a_{n}
\end{array}\right)\left(\begin{array}{llll}
s_{1} & & & 0 \\
& & s_{2} & \\
& & \ddots & \\
0 & & & s_{n}
\end{array}\right)=
$$

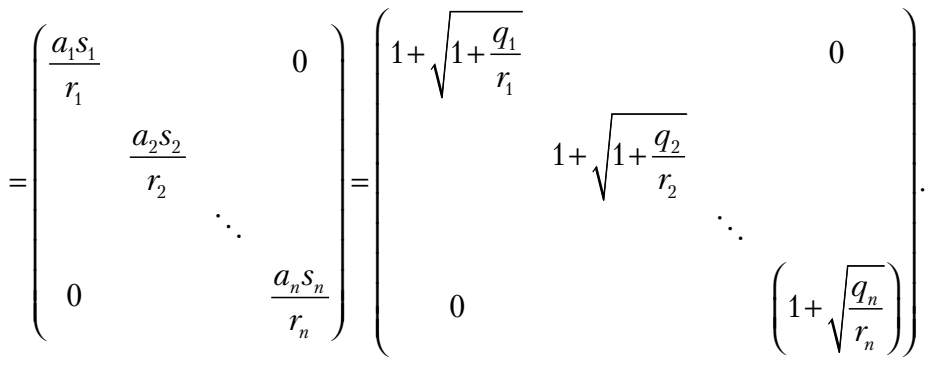

Substituting now (19) into (15), let's obtain the desired expression for control:

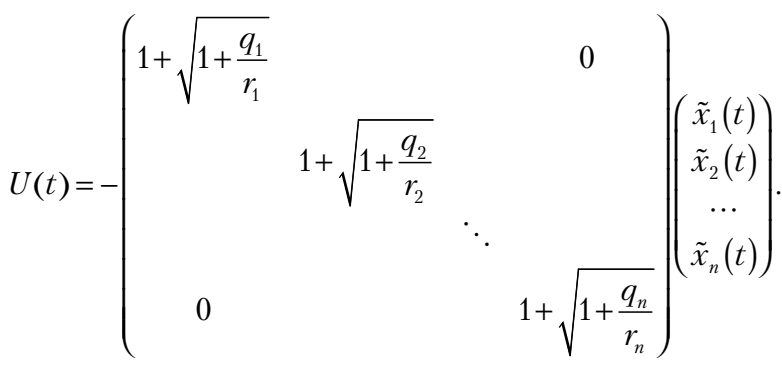

This implies independent relations for the components of the control vector:

$$
\begin{gathered}
u_{j}(t)=-\tilde{x}_{j}(t)\left(1+\sqrt{1+\frac{q_{j}}{r_{j}}}\right)=-\left(x(t)_{j}-x_{j}^{0}(t)\right)\left(1+\sqrt{1+\frac{q_{j}}{r_{j}}}\right)=\left(x_{j}^{0}(t)-x_{j}(t)\right) d_{j}, \\
d_{j}=1+\sqrt{1+\frac{q_{j}}{r_{j}}}, \quad j=1,2, \ldots, n .
\end{gathered}
$$

From (20) it follows that the sign of the control action for each component is determined by the sign of the current deviation of this state component from the reference value, and the control value is proportional to the deviation.

It should be noted that in the portfolio control task under consideration, the obtained control may turn out to be costly, that is, the total cost of acquiring the required types of assets in an amount determined by (20) can exceed the total profit from the assets sold. In this regard, let's formulate the problem of finding a cost-free control that minimally deviates from optimal.

Let's introduce

$Z_{j}(t)$ - adjusted control action on the $\mathrm{j}$-th asset, $j=1,2, \ldots, n$.

Let's pose the problem of finding a set $Z_{j}(t), \quad j=1,2, \ldots, n$, minimizing 


$$
L(Z(t))=\sum_{j=1}^{n}\left(Z_{j}(t)-u_{j}(t)\right)^{2}
$$

and providing zero costs for the implementation of control, that is, satisfying the restriction

$$
\sum_{j=1}^{n} a_{j} Z_{j}(t)=0
$$

Let's solve this problem by the method of indefinite Lagrange multipliers. Let's introduce the Lagrange function

$$
\Phi(Z(t))=\sum_{j=1}^{n}\left(Z_{j}(t)-u_{j}(t)\right)^{2}-\lambda\left(\sum_{j=1}^{n} a_{j} Z_{j}(t)\right) .
$$

Next

$$
\frac{d \Phi(Z(t))}{d Z_{j}(t)}=2\left(Z_{j}(t)-u_{j}(t)\right)-\lambda a_{j}=0,
$$

whence

$$
Z_{j}(t)=\frac{1}{2} \lambda a_{j}+u_{j}(t), \quad j=1,2, \ldots, n
$$

Substitute (23) in (22):

$$
\sum_{j=1}^{n} a_{j}\left(\frac{1}{2} \lambda a_{j}+u_{j}(t)\right)=\frac{1}{2} \lambda \sum_{j=1}^{n} a_{j}^{2}+\sum_{j=1}^{n} a_{j} u_{j}(t)=0 .
$$

Hence

$$
\frac{1}{2} \lambda=-\frac{\sum_{j=1}^{n} a_{j} u_{j}(t)}{\sum_{j=1}^{n} a_{j}^{2}}
$$

Now, substituting (24) in (23), let's obtain the expression for the adjusted control action:

$$
Z_{j}(t)=-a_{j} \frac{\sum_{j=1}^{n} a_{j} u_{j}(t)}{\sum_{j=1}^{n} a_{j}^{2}}+u_{j}(t)
$$

A direct verification shows that the set $Z_{j}(t)$ obtained in accordance with (23) satisfies (22). Finally, using relation (25), let's obtain the final expression for the adjusted control. Substituting (20) into (25)

$$
Z_{j}(t)=\left(x_{j}^{0}(t)-x_{j}(t)\right)\left(1+\sqrt{1+\frac{q_{j}}{r_{j}}}\right)-a_{j} \frac{\sum_{j=1}^{n} a_{j}\left(x_{j}^{0}-x_{j}(t)\right)\left(1+\sqrt{1+\frac{q_{j}}{r_{j}}}\right)}{\sum_{j=1}^{n} a_{j}^{2}}, j=1,2, \ldots, n
$$




\section{Research results of the problem of forming a portfolio of securities under uncertainty con- ditions, taking into account the dynamics of assets}

1. A method is proposed and justified for solving the problem of forming a portfolio of securities under uncertainty conditions in the initial data by a probabilistic criterion. The problem is reduced to optimizing the quadratic fractional criterion.

2. A method is proposed and justified for solving the problem of forming a portfolio of securities in the case when only the values of its statistical characteristics (mathematical expectation and variance) are known with respect to the distribution density of the random value of assets.

3. A method is proposed and justified for solving the dynamic problem of forming a portfolio of securities when asset values change randomly in time. The problem is solved by the methods of the general theory of optimal control based on the solution of the Riccati equation.

\section{Discussion of the results of solving the set of tasks of forming a portfolio of securities}

The paper considers various models and methods for solving the problem of forming a portfolio of securities, depending on the level of awareness regarding the values of the statistical characteristics of random asset returns. In this case, the canonical problem of forming a portfolio of securities by the criterion of minimizing the risk of a portfolio at a given level of profitability is reduced to the problem of quadratic mathematical programming. It is shown that an adequate account of the real variances of assets makes it expedient to switch to another criterion: the probability of a random value exceeding the portfolio profitability of a given acceptable threshold. The advantages of this approach are determined by the important properties of the resulting solution: it is controlled by setting an acceptable level of profitability and is guaranteeing, minimizing the level of danger of random failure results.

In situations where the sample of initial data is small, it is proposed to solve the problem of forming a portfolio for the "worst" density distribution of portfolio profitability, for which the probability of not reaching an acceptable threshold is maximum. The problem is solved by the methods of the new mathematical apparatus of continuous linear programming.

The paper proposes a new approach to solving the problem of portfolio formation, an important advantage of which is to take into account the dynamics of the value of assets. The problem is solved in terms of a general control theory based on the solution of the Riccati equation. Moreover, the model of dynamics of a controlled system proposed in the work made it possible to overcome the well-known difficulties of solving differential equations of this type.

Reasonable directions for further research are related to the development of methods for solving the portfolio problem for insufficiently studied models of the uncertainty of the source data. Moreover, situations when this uncertainty is described in terms of fuzzy [18] or inaccurate [23] mathematics are the most interesting and important in theoretical and practical respects. Possible approaches to solving the problem in these cases are proposed in [24-26].

\section{Conclusions}

The analysis of traditional methods is done for solving the problem of forming a portfolio of securities by the criterion - the minimum variance of the random portfolio profitability.

A method for solving a portfolio problem for a situation where the variance of assets is large is developed. At the same time, another more adequate optimization criterion is used to solve the problem - the probability that the total portfolio return will take a value no lower than a given threshold.

A method has been developed for solving the portfolio formation problem when the distribution density of assets' return on assets is not known, but based on the results of statistical processing of the source data, estimates of the main statistical characteristics of return on assets (mean and variance) are obtained. To solve the problem in this case, a minimax approach is used, based on finding the worst distribution density of the total portfolio return.

A distinctive feature of the problem posed and solved in the work is the rejection of its traditional static formulation and the transition to a dynamic description of the behavior of the financial environment, taking into account the realities of the market situation. In accordance with this, the task of forming a portfolio of securities is solved in terms of a general theory of control. The method is based on solving the Riccati equation. 


\section{References}

[1] Gurin, L. S., Dymarskiy, Ya. S., Merkulov, A. D. (1968). Zadachi i metody optimal'nogo raspredeleniya resursov. Moscow: Sovetskoe radio, 368.

[2] Larichev, O. I. (2002). Teoriya i metody prinyatiya resheniy. Moscow: Logos, 392.

[3] Bazaraa, M. S., Shetty, C. M. (1979). Nonhnear Programming: Theory and Algorithms. Wiley, 312.

[4] Raskin, L. G. (1976). Analiz slozhnyh sistem i ehlementy teorii upravleniya. Moscow: Sovetskoe radio, 344.

[5] Karmanov, V. G. (1980). Matematicheskoe programmirovanie. Moscow, 256.

[6] Himmelblau, D. (1972). Applied Nonlinear Programming. McGraw-Hill, 498.

[7] Zangwill, W. I. (1969). Nonlinear Programming: A Unified Approach. PrenticeHall, 356.

[8] Yudin, D. B. (1974). Matematicheskie metody upravleniya v usloviyah nepolnoy informatsii. Zadachi i metody stohasticheskogo programmirovaniya. Moscow: Sovetskoe radio, 392.

[9] Demutskiy, V. P., Pignastyy, O. M. (2003). Teoriya predpriyatiya. Ustoychivost' funktsionirovaniya massovogo proizvodstva i prodvizheniya produktsii na rynok. Kharkiv: KhNU im. V. N. Karazina, 272.

[10] Pignastiy, O. M. (2005). Stohasticheskoe opisanie ehkonomiko-proizvodstvennyh sistem s massovym vypuskom produktsii. Doklady Nats. Akad. Nauk Ukrainy, 7, 66-71.

[11] Pignastiy, O. M. (2007). Stohasticheskaya teoriya proizvodstvennyh sistem. Kharkiv: KhNU im. V. N. Karazina, 387.

[12] Raskin, L. G., Kirichenko, I. O., Seraya, O. V. (2013). Prikladnoe kontinual'noe lineynoe programmirovanie. Kharkiv, 293.

[13] Seraya, O. V., Demin, D. A. (2012). Linear Regression Analysis of a Small Sample of Fuzzy Input Data. Journal of Automation and Information Sciences, 44 (7), 34-48. doi: https://doi.org/10.1615/jautomatinfscien.v44.i7.40

[14] Raskin, L. G., Seraya, O. V. (2003). Formirovanie skalyarnogo kriteriya predpochteniya po rezul'tatam poparnyh sravneniy obektov. Sistemnyy analiz, upravlenie i informatsionnye tehnologii. Vestnik NTU «KhPI», 6, 63-68.

[15] Connor, G., Goldberg, L. R., Korajczyk, R. A. (2010). Portfolio Risk Analysis. Princeton University Press. doi: https://doi.org/ $10.1515 / 9781400835294$

[16] Otani, Y., Imai, J. (2013). Pricing Portfolio Credit Derivatives with Stochastic Recovery and Systematic Factor. IAENG International Journal of Applied Mathematics, 43 (4), 176-184.

[17] Read, C. (2012). The Portfolio Theorists: von Neumann, Savage, Arrow and Markowitz. Palgrave Macmillan. doi: https:// doi.org/10.1057/9780230362307

[18] Bellman, R. E., Zadeh, L. A. (1970). Decision-Making in a Fuzzy Environment. Management Science, 17 (4), B-141-B-164. doi: https://doi.org/10.1287/mnsc.17.4.b141

[19] Sira, O., Katkova, T. (2017). Formation of securities portfolio under conditions of uncertainty. Eastern-European Journal of Enterprise Technologies, 1 (4 (85)), 49-55. doi: https://doi.org/10.15587/1729-4061.2017.92283

[20] Orlovskiy, S. A. (1981). Problemy prinyatiya resheniy pri nechetkoy informatsii. Moscow: Nauka, 264.

[21] Atans, M. (1968). Optimal'noe upravlenie. Moscow: Mashinostroenie, 764.

[22] Brayson, A. (1972). Prikladnaya teoriya optimal'nogo upravleniya. Moscow: Mir, 544.

[23] Pawlak, Z. (1991). Rough Sets: Theoretical Aspects of Reasoning about Data. Dordrecht: Kluwer Academic Publisher. doi: https://doi.org/10.1007/978-94-011-3534-4

[24] Raskin, L., Sira, O. (2016). Method of solving fuzzy problems of mathematical programming. Eastern-European Journal of Enterprise Technologies, 5 (4 (83)), 23-28. doi: https://doi.org/10.15587/1729-4061.2016.81292

[25] Raskin, L., Sira, O. (2016). Fuzzy models of rough mathematics. Eastern-European Journal of Enterprise Technologies, 6 (4 (84)), 53-60. doi: https://doi.org/10.15587/1729-4061.2016.86739

[26] Raskin, L., Sira, O., Ivanchykhin, Y. (2017). Models and methods of regression analysis under conditions of fuzzy initial data. Eastern-European Journal of Enterprise Technologies, 4 (4 (88)), 12-19. doi: https://doi.org/10.15587/1729-4061.2017.107536

Received date 09.07.2019

Accepted date 21.08.2019

Published date 30.11.2019
(C) The Author(s) 2019

This is an open access article under the CC BY license (http://creativecommons.org/licenses/by/4.0). 